\title{
Impact of the Azores Front Propagation on Deep Ocean Particle Flux
}

\author{
Birte Fründt*, Joanna J. Waniek \\ Leibniz-Institut für Ostseeforschung Warnemünde, \\ Seestraße 15, 18119 Rostock, Germany
}

Received 22 June 2012; accepted 16 August 2012

\begin{abstract}
The Azores Current originating as a branch of the Gulf Stream is a highly dynamic system in the subtropical North Atlantic. The associated front forms the northeastern boundary of the North Atlantic Subtropical Gyre. In this study we analyzed 42 years of assimilated modeled temperature fields to localize the position of the Azores Front at $22^{\circ} \mathrm{W}$ and observed a fast north- and southward propagation between $30^{\circ} \mathrm{N}$ and $37^{\circ} \mathrm{N}$ on monthly to decadal time scales. The North Atlantic Oscillation with correlated changes of the wind direction was identified as one driving mechanism. As the front is acting as a guide for Rossby waves, the signal of the front's propagation is transferred to the western Atlantic and, among other atmospheric forcing mechanisms, induces a shifting of the Northern Wall of the Gulf Stream with one year delay. Shallower mixed layer depths in the northern frontal region of the Azores Current caused by the rise of the isotherms lead to nutrient supply and primary production different from those found in the southern frontal region of the current system. A high interannual variability is manifested in deep ocean particle flux, derived from a sediment trap in $2000 \mathrm{~m}$ water depth at the mooring site KIEL276 $\left(33^{\circ} \mathrm{N}, 22^{\circ} \mathrm{W}\right)$ from 1993 to 2008 , which is directly related to the phytoplankton bloom in the euphotic zone. This variability is explained by the propagation of the front and strong variations in the catchment areas of the sediment trap due to the associated eddy activity in the frontal region.
\end{abstract}

Keywords: Azores Front $\cdot$ deep ocean particle flux North Atlantic Oscillation• Gulf Stream

(c) Versita Sp. z o.o.

\section{Introduction}

South of Newfoundland near $39^{\circ} \mathrm{N}$, the Gulf Stream branches into the North Atlantic Current and the Azores Current $(\mathrm{AC})[1,2]$. The $\mathrm{AC}$ itself transports $10 \mathrm{~Sv}$ in the upper $800 \mathrm{~m}$ of the water column across the Atlantic Ridge south of the Azores between $32^{\circ} \mathrm{N}$ and $36^{\circ} \mathrm{N}[3]$ and then feeds the southwestward flowing North Equatorial Current [2]. Accompanied to the eastward flow of the meandering

*E-mail: birte.fruendt@io-warnemuende.de
$A C$ is a high mesoscale eddy activity causing recirculation and advection [4]. The northern boundary of the AC is formed by the Azores Front (AF, Fig. 1) characterized by strong temperature and salinity gradients [5], located between $30^{\circ} \mathrm{N}$ and $38^{\circ} \mathrm{N}$ [6], whereby the front simultaneously represents the northeastern border of the North Atlantic Subtropical Gyre. The AF separates the warmer and saltier $18^{\circ} \mathrm{C}$ Western North Atlantic Water (WNAW) originating from the Sargasso Sea to the south from the colder Eastern North Atlantic Water (ENAW) to the north $[4,7]$ and in this study is defined by rising of the $15^{\circ} \mathrm{C}-$ isotherm from depths below $300 \mathrm{~m}$ to above $200 \mathrm{~m}$ [1]. The northwestern boundary of the North Atlantic Sub- 


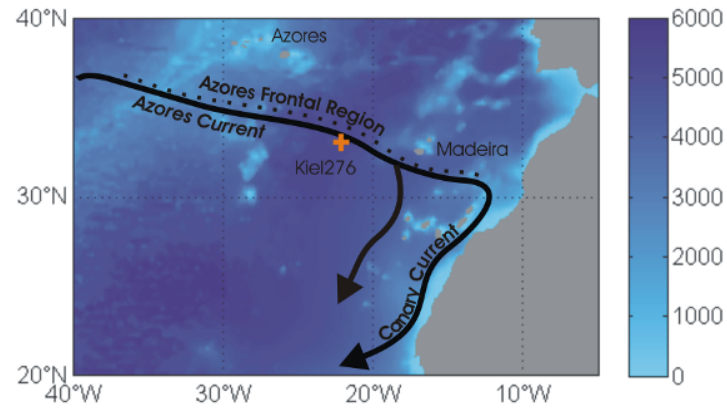

Figure 1. The Azores Frontal Region in the subtropical Northeast Atlantic. Indicated are the Azores Current with its accompanied Azores Frontal Region, building the transition area between the surface waters of the cold waters of the temperate Atlantic and the warm waters of the subtropical and tropical Atlantic, and the Canary Current. The time series station $\mathrm{KIEL} 276$ is located on $33^{\circ} \mathrm{N}, 22^{\circ} \mathrm{W}$.

tropical Gyre is formed by the Gulf Stream. North- and southward drifting of the Gulf Stream has been observed and studied before (e.g. [8-11]). Combined surface, aircraft and satellite observations have been used to observe the north wall of the Gulf Stream since 1966 [9]. A major factor in establishing the position of the Gulf Stream was found in changes of the atmospheric forcing related to the North Atlantic Oscillation (NAO) being the dominant mode in the climatic variability of the North Atlantic $[12,13]$. Correlated to the NAO, changes in wind forcing and the sea surface temperature (SST) pattern influence the north- and southward shift of the Gulf Stream $[10,11]$. The origin of the $A C$ as a branch of the Gulf Stream suggests a correlation of their propagation.

In contrast to the large scale physical forcing mechanisms from the atmosphere and in the ocean, subtropical fronts generate highly dynamic systems that can maintain a strong biological response caused both by their large spatial extent and temporal persistence as well as their jet-like flows [14]. Closely located to the AF is the mooring station KIEL276 $\left(33^{\circ} \mathrm{N}, 22^{\circ} \mathrm{W}\right.$, Fig. 1) where particle flux was sampled in $2000 \mathrm{~m}$ from 1993 onwards. This particle flux time series will be used to study the influence of the propagation and the water mass separation of the front on the biological environment in the upper water column and associated export production. Many studies of the biological production in the region of the AF have been carried out, e.g. by refs $[5,7,14,15]$ with analyses of biological and chemical data sampled on different cruises. However, no long time series of in-situ chlorophyll $a$ or primary production which are relevant for studies of the biogenic particle flux are available. Ref. [15] found, in the colder water north of the front, higher concentrations than in the warmer water in the south caused by either more nutrient supply or generally higher nutrient concentrations. However, there was no evidence of higher chlorophyll $a$ values in the frontal zone, and also no indication for differences in the integrated production rates down to $80 \mathrm{~m}$ water depth north and south of the AF [14]. Contrary to ref. [15], ref. [14] measured 2 to 3 times higher chlorophyll $a$ values at the frontal boundary. Ref. [7] summarized the results of 13 cruises in the frontal region and found no significant differences in primary production rates related to the position of the front. Interannual variability in the biogenic particle flux [16] could not be explained since related dynamics on the upper water column caused by propagation of the AF were not well understood. Ref. [16] showed high variability in surface production based on model results and remotely measured chlorophyll $a$, but did not provide any explanation which processes are responsible for such results.

In this study we analyze the north- and southward propagation of the AF using assimilated model data from 1966 to 2007.

At first we identify driving mechanisms as well as consider the interaction with the Gulf Stream. Secondly, the influence of the front on the deep ocean particle flux is analyzed regarding the special growth conditions in the frontal zone as a narrow transition area between the oligotrophic subtropics and the more productive temperate North Atlantic.

\section{Material and Methods}

The AF does not have any surface indication throughout the year, especially in summer, as it is masked by the seasonal thermocline, thus ruling out detection via satellite observations of the sea surface temperature. Also the use of the remotely measured sea surface height is hindered because these signals are dominated by mainly atmospherically forced temperature changes of the uppermost water column above the front in 200 to $300 \mathrm{~m}$ water depth. However, these temperature changes do not influence the position of the AF.

For studying the propagation of the AF on monthly to decadal time scales, modeled temperature fields in the Northeast Atlantic have been used, as in-situ measurements of the front are rare (Table 1).

Temperature data from the Simple Ocean Data Assimilation Parallel Ocean Program (SODA POP) were used. The model provides oceanographic fields with a mean spatial resolution of $0.5^{\circ} \times 0.5^{\circ} \times 40$ depth levels and monthly resolution, between 1958 and 2007. This ocean model assimilates hydrographic data, temperature and salinity 
Table 1. Cruises in the Northeast Atlantic from which temperature measurements were used to reconstruct the position of the Azores Front (Fig. 2).

\begin{tabular}{lllll}
\hline Site no. & Cruise & Cruise period & Research Vessel & Reference \\
\hline \hline 1 & P86 & $15 / 03 / 82-27 / 04 / 82$ & Poseidon & {$[6]$} \\
2 & P104 & $17 / 10 / 83-22 / 10 / 83$ & Poseidon & \\
3 & M2T069-5-6 & $21 / 10 / 84-21 / 11 / 84$ & Meteor II & \\
4 & MET006 & $01 / 11 / 87-09 / 11 / 87$ & Meteor III & {$[46]$} \\
5 & M10/1 & $19 / 03 / 89-27 / 04 / 89$ & Meteor III & {$[47]$} \\
6 & M36/2 & $21 / 06 / 96-18 / 07 / 96$ & Meteor III & {$[5]$} \\
7 & AZORES I & August 1998 & BIO Hesperides & {$[4]$} \\
8 & P247/2 & January 1999 & Poseidon & \\
9 & P259 & $10 / 04 / 00-21 / 04 / 00$ & Poseidon & \\
10 & P267 & $13 / 01 / 01-29 / 01 / 01$ & Poseidon & \\
11 & P297 & $17 / 04 / 03-28 / 04 / 03$ & Poseidon & \\
12 & P321 & $02 / 05 / 05-11 / 05 / 05$ & Poseidon & \\
13 & P334 & $15 / 03 / 06-03 / 04 / 06$ & Poseidon & \\
14 & P349 & $05 / 04 / 07-24 / 04 / 07$ & Poseidon & \\
\hline
\end{tabular}

data from moorings, CTD measurements and ARGO floats, surface temperature and salinity observations of different kinds and nightly infrared satellite SST data. For more details see ref. [17] and ref. [18].

To obtain the frontal position, the temperature distribution at $22^{\circ} \mathrm{W}$ between $20^{\circ} \mathrm{N}$ to $40^{\circ} \mathrm{N}$ from surface to 400 $\mathrm{m}$ water depth was determined by linearly interpolating 18 depth levels of the model to a vertical resolution of one meter. According to the definition of the AF [1], the position of the front in north-south direction was set where the $15^{\circ} \mathrm{C}$ - isotherm crosses $250 \mathrm{~m}$ water depth.

The $22^{\circ} \mathrm{W}$ longitude was chosen to compare the position of the AF determined from the SODA POP model data with in-situ measurements of the front made along $22^{\circ} \mathrm{W}$ transects between 1982 and 2007 (Table 1) which are independent from the model assimilation.

All the analyses carried out in this study are confined to a region which ranges from the southernmost position of the AF in the time series to the northernmost position. Furthermore one degree in latitude is added, respectively, regarding the slope of the $15^{\circ} \mathrm{C}$ - isotherm at the front's position. Thus, in this study the so called frontal region extends from $29^{\circ} \mathrm{N}$ to $38.5^{\circ} \mathrm{N}$.

The influence of the atmospheric forcing on the position of the AF is analyzed by considering the NAO. The NAOindex describes the difference of the normalized sea level pressure anomaly between the Azores High and the Iceland Low [19]. Here both, the monthly NAO-index and the winter NAO-index covering December to March, were used. The data are available at http://www.cgd.ucar.edu. Additionally, the wind direction over the North Atlantic was taken into account. Wind directions at $22^{\circ} \mathrm{W}$ were calculated from monthly means of NCEP (National Centers for Environmental Prediction) zonal and meridional wind components (available at http://www.esrl.noaa.gov) [20]. Anomalies of the wind direction were calculated by subtracting the long term mean from the actual wind direction. The wind components were also used to calculate the Ekman transport on $22^{\circ} \mathrm{W}[21,22]$.

In this study the Gulf Stream Northern Wall (GSNW) index - calculated as the first principal component of the position of the North Wall Gulf Stream by ref. [9] - was applied from 1966 to 2007, and obtained from www.pml-gulfstream.org.uk. The units of the GSNWindex are equivalent to a meridional shifting of $0.03^{\circ}$ at $79^{\circ} \mathrm{W}$ and $0.3^{\circ}$ at $65^{\circ} \mathrm{W}[8]$.

To distinguish the conditions for the biological production north and south of the AF, the mixed layer depth (MLD) was derived from the temperature profiles of SODA-POP as the depth where the difference between the SST and the temperature in depth exceeds $0.5^{\circ} \mathrm{C}$ [23]. The winter mixing is one of the crucial parameters that influence the strength of the phytoplankton bloom [24]. According to the depth of the mixed layer different amounts of nutrients are delivered to the euphotic zone. For the determination of the MLD north and south of the AF, the temperature profiles $1^{\circ}$ north and south of the calculated position of the AF were used.

Variability of the biological export production in the upper water column was analyzed by using particle flux data from a sediment trap in $2000 \mathrm{~m}$ from the mooring station KIEL276 (Table 2, [16]) located at $33^{\circ} \mathrm{N}, 22^{\circ} \mathrm{W}$, which is frequently passed by the AF. From satellite derived chlorophyll $a$ data an estimate of the biological production in the whole euphotic zone cannot be made due to the deep chlorophyll maximum (DCM) at approximately $100 \mathrm{~m}$ water depth. This DCM is a consistent oceanographic feature of the subtropical ocean [25]. The particle flux used in 
this study is directly coupled to the phytoplankton development and decay in the euphotic zone [16] with a delay of one and a half to two months [26]. The particle flux data were sampled with $0.5 \mathrm{~m}^{2}$ sediment traps in $2000 \mathrm{~m}$ depth. These instruments, consisting of fibre glass reinforced cone with a funnel slope [16], are described in detail by ref. [27]. The sampling bottles $\left(400 \mathrm{~cm}^{3}\right.$ polypropylene cups) were attached to a carousel which allows temporally separated sampling intervals of 5 to 62 days. Choice of sampling interval length depends on the seasonality of biological production $[16,26]$. The data gaps both between June 1997 and February 1999 and between 2000 and 2001 are caused by mooring failure [16]. For a detailed description of the sample treatment and the determination of the particle flux see ref. $[16,28]$. For a better comparison with the monthly resolved SODA-POP data and derived quantities such as MLD, monthly mean values of the particle flux were calculated with the assumption that the means of the different sampling intervals are valid for each day of the associated interval.

As the mooring station KIEL276 is located close to the $\mathrm{AF}$, changes in the catchment areas of the sediment trap due to variances in the current directions can determine whether the particle flux originates from north or south of the front. The catchment areas were calculated by using the method introduced in ref. [29]. Daily current measurements of Aanderaa current meters (RCM 7 and 8) from the mooring in different depths between surface and $1600 \mathrm{~m}$ water depth were used (see Table 2). The currents are shown in e.g. ref. [30] (1980-2000) and ref. [16] (19952002). The catchment areas of winter and spring 1994 as well as from February 1999 to July 2001 were calculated using monthly current data of SODA-POP in their highest depth-resolution because, due to instrument failures, no in-situ measurements from the mooring are available. For all calculations a settling velocity of $100 \mathrm{~m} \cdot \mathrm{day}^{-1}$ of the sinking particles in the water column down to $2000 \mathrm{~m}$ is used [29]. Catchment areas from 1994 to 2001 are described in detail by ref. [16].

Nitrate samples of the Poseidon cruise P349 in April 2007 (Table 1) determined by an autoanalyzer (EVOLUTION III, Alliance Instruments) according to standard methods [31], were used to calculate exemplary the supply of dissolved nitrate to the upper water column after the deepening of the mixed layer in winter both north and south of the AF. The cruise took place after the spring bloom which occurs between January and March in the subtropical Northeast Atlantic [16] and therefore nitrate was depleted in the upper water column. Discrete measurements were carried out for samples from 10, 30, 70 (90), 130, 200, 400 or $500 \mathrm{~m}$ water depth (brackets indicate depths of water sample taken south of the front according to different depths of the nitracline).

\section{Results and Discussion}

\subsection{Driving Mechanisms}

The position of the AF shows a large month to month variability (Fig. 2a) caused by eddies moving across $22^{\circ} \mathrm{W}$ influencing the depth of the $15^{\circ} \mathrm{C}$ - isotherm and therefore the frontal position according to our definition.

In 42 years from 1966 to 2007 the northernmost position of the front was found in 1975 and 2004 at $37.5^{\circ} \mathrm{N}$ while the southernmost position was seen at $30^{\circ} \mathrm{N}$ in 2004 (Fig. 2a). The mean position between 1966 and 2007 was estimated at $33.9 \pm 1.3^{\circ} \mathrm{N}$.

The longer term changes of the front's propagation are becoming clearer after applying a running mean over 36 months. At the beginning of the time series until 1970 the AF on average remains approximately at $33.2^{\circ} \mathrm{N}$. From 1970 to 1974 a northward movement is seen, reaching $34.1^{\circ} \mathrm{N}$ in 1974 . In the following three years the $A F$ shifted southward to reach $33.4^{\circ} \mathrm{N}$ in 1977 . For the next seven years the AF propagates northward to approach $34.7^{\circ} \mathrm{N}$ in 1984 , followed by three years southward propagation, with the $A F$ detected at $33.2^{\circ} \mathrm{N}$ in 1987 . After seven years of northward moving, the AF can be detected at $34.8^{\circ} \mathrm{N}$ in 1994 . The AF repeatedly drifted southward over three years to $33.1^{\circ} \mathrm{N}$ in 1997 , followed by a three years northward propagation to $34.4^{\circ} \mathrm{N}$ (Fig. 2a).

A shorter period of southward propagation follows from 2000 to 2002. From 2002 onwards, the AF tends northward to the northernmost position determined in the running-mean time series at $35.2^{\circ} \mathrm{N}$ in 2005 , and to the end of the time series a southward drift proceeds (Fig. 2a). From 1977 to 1997 the propagation of the AF shows a repeated pattern of three years southward followed by seven years northward movement, with the southward movement being faster $\left(150 \pm 40 \mathrm{~m} \cdot \mathrm{day}^{-1}\right)$ than the northward movement $\left(93 \pm 16 \mathrm{~m} \cdot \mathrm{day}^{-1}\right)$. From 1997 onwards an obvious period of northward or southward propagation of the front is no longer clearly detectable (Fig. 2a). Over the entire time series a linear northward propagation of the AF of $6 \mathrm{~m} \cdot \mathrm{day}^{-1}$ was calculated.

Measurements from 14 expeditions (Table 1) - which, to our knowledge, are not assimilated into the SODA-POP model - are also included in Fig. 2a to estimate the quality of the SODA POP model data. The measured data compared to the model output show an agreement in the position of the $A F$ within $0.5^{\circ}$; this is the same as the spatial resolution in latitude of the model data. The distances between the stations of the cruises are similar with approximately 30 nautical miles. 
Table 2. Sample series of the deep ocean particle flux from the mooring station $\mathrm{KIEL} 276\left(33^{\circ} \mathrm{N}, 22^{\circ} \mathrm{W}\right)$. Additionally the current meter data are given from which the catchment areas were calculated [16, 29].

\begin{tabular}{llll}
\hline Sample Series & Start of deployment & End of deployment & Current meter depth $[\mathrm{m}]$ \\
\hline \hline 14 & $20 / 09 / 1993$ & $05 / 08 / 1994$ & SODA-POP \\
15 & $27 / 09 / 1994$ & $29 / 08 / 1995$ & $240,500,970,1120$ \\
16 & $01 / 11 / 1995$ & $12 / 06 / 1996$ & $378,1008,1600$ \\
17 & $14 / 07 / 1996$ & $15 / 06 / 1997$ & $270,500,1000,1600$ \\
19 & $01 / 02 / 1999$ & $01 / 11 / 1999$ & SODA-POP \\
21 & $03 / 02 / 2001$ & $31 / 07 / 2001$ & SODA-POP \\
22 & $24 / 02 / 2002$ & $01 / 04 / 2003$ & $240,500,1000,1600$ \\
23 & $24 / 04 / 2003$ & $16 / 03 / 2004$ & $240,500,1000,1600$ \\
24 & $20 / 03 / 2004$ & $01 / 04 / 2005$ & $240,500,1038,1594$ \\
25 & $10 / 05 / 2005$ & $01 / 04 / 2007$ & $240,500,1015,1570$ \\
26 & $01 / 05 / 2007$ & $26 / 04 / 2009$ & $240,500,1015,1572$ \\
\hline
\end{tabular}
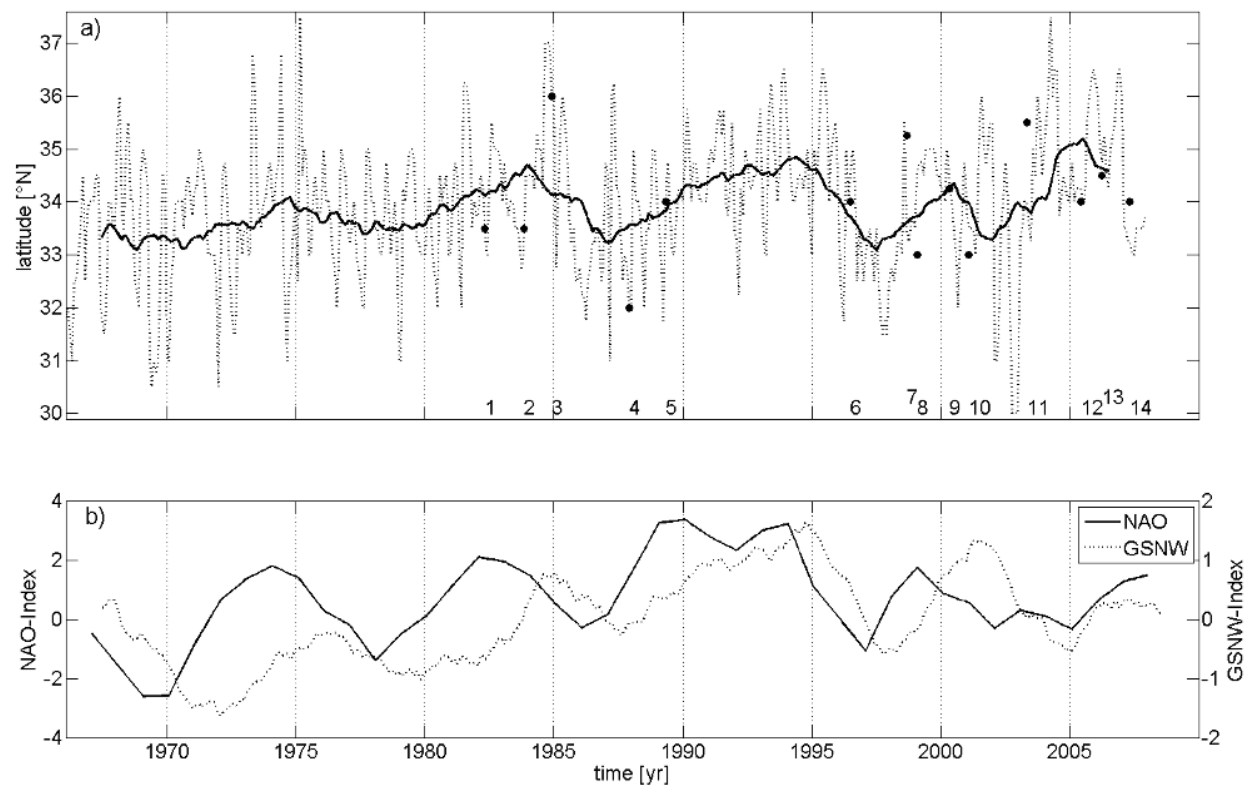

Figure 2. a) Position of the Azores Front at $22^{\circ} \mathrm{W}$ from 1966 to 2007 derived from the SODA POP temperature distribution, in monthly resolution (dashed line) and a running mean over 36 months (solid line). The circles and numbers indicate in-situ measurements of the Azores Front at $22^{\circ} \mathrm{W}$ (see Table 2). b) Running mean over 3 years of the winter-NAO-index (solid line) and running mean over 36 months of the GSNW-index (dashed line) from 1966 to 2009.

The influence of the NAO on the ocean dynamics in the permanent thermocline in the Northeast subtropical Atlantic was shown in previous studies (e.g. ref. [30]). The time series of the running mean over three years of the winter NAO-Index (Fig. 2b) shows a similar pattern as the latitudinal movement of the position of the AF. From 1970 to 1990, the NAO-index ascends and descends with a period of eight years. After 1990 this period decreases and at the end of the time series no period can be recognized.
The position of the AF seems to respond to the NAO with a delay of approximately one year. Significant correlations (significance level $<95 \%$ ) were found with a lag of 9-12 months with the largest coefficient of $\rho=0.15$ (Table 3). Correlation coefficients between the winter NAOindex and an annual mean of the position of the AF were calculated, because the NAO is most pronounced in winter [13]. Significant correlations $(\rho=0.57)$ can be seen where the AF lags the NAO by 1 year (Fig. 3, Table 3).

As the dominant atmospheric feature over the North At- 
Table 3. Time lags of calculated correlation coefficients (in brackets) with their significance level (1: $95 \%, 2: 99 \%, 3: 99.9 \%$ as superscript numbers), between NAO and GSNW, NAO and position of the AF, position of the AF and GSNW, and GSNW and position of the AF in monthly and annual resolution with the first variable leading the second, respectively. For time ranges over several months the highest coefficient is given.

\begin{tabular}{lllllll}
\hline \multicolumn{2}{c}{ NAO \& GSNW } & \multicolumn{2}{c}{ NAO \& AF } & \multicolumn{2}{c}{ AF \& GSNW } & \multicolumn{2}{c}{ GSNW \& AF } \\
\hline monthly & annual & monthly & annual & monthly & annual & monthly \\
\hline \hline $8-12(0.13)^{2}$ & $0(0.36)^{1}$ & $9-12(0.15)^{2}$ & $0(0.32)^{1}$ & $0-21(0.23)^{3}$ & $1(0.45)^{2}$ & $0(0.15)^{2}$ \\
$21-23(0.16)^{3}$ & $1(0.51)^{3}$ & $14-15(0.1)^{1}$ & $1(0.57)^{3}$ & $24-28(0.14)^{2}$ & $2(0.41)^{2}$ & $45-47(0.12)^{2}$ \\
$29-32(0.16)^{3}$ & $2(0.61)^{3}$ & $20-21(0.12)^{2}$ & & $77-90(0.19)^{3}$ & $7(0.4)^{1}$ & $53-56(0.15)^{2}$ \\
& $3(0.35)^{1}$ & & & $115-120(0.23)^{3}$ & $10(0.47)^{2}$ & \\
& & & & & \\
\hline
\end{tabular}

lantic, the NAO is associated with changes in wind direction, especially of the surface westerlies between roughly $40^{\circ} \mathrm{N}$ and $60^{\circ} \mathrm{N}$, but also in the horse latitudes between approximately $25^{\circ} \mathrm{N}$ and $35^{\circ} \mathrm{N}$ [13]. In this region where the AF is mostly located, fluctuations of the wind directions $\left(0^{\circ}\right.$ pointing northwards, $90^{\circ}$ pointing eastwards) directly associated with the NAO have been determined. Considering the wind direction anomaly at $22^{\circ} \mathrm{W}$ directly north $\left(35^{\circ} \mathrm{N}\right)$ and south $\left(32.5^{\circ} \mathrm{N}\right)$ of the mean position of the front (Fig. 4), deviations from the mean directions influence the position of the AF. The mean direction at these latitudes are both southward $\left(170^{\circ} \pm 80^{\circ}\right.$ at $35^{\circ} \mathrm{N}$ and $190^{\circ} \pm 70^{\circ}$ at $32.5^{\circ} \mathrm{N}$ ), connected to a strong variability indicated by high standard deviations. Changes in the wind direction which are directly associated with the NAO are one explanation for a propagation of the AF (Fig. 4). This fact is supported by the study of ref. [32] which calculated the highest correlation between the wind stress curl and the AF characterized by the eddy kinetic energy, at a time lag of about seven months. Both results are in the same order of magnitude, however, the difference of two months in comparison to our calculation (Table 3) may be related to the different definitions of the position of the AF; in this study the temperature distribution is used whereas the eddy kinetic energy was used by ref. [32]. The time lag between the NAO and the position of the AF of several months is caused by the adjustment of the upper water column to the large scale atmospheric forcing [32].

According to the southward mean wind direction in the frontal area, a positive anomaly corresponds to a westward and a negative anomaly to an eastward deviation of the mean wind direction. A westward directed wind leads to a northward displacement of the AF relative to the mean position, while an eastward directed wind leads to a more southern position of the front, causing the front to move approximately $90^{\circ}$ right to the wind direction, pointing towards a wind induced Ekman transport affect- ing north- and southward shifting of the front (Fig. 4). To confirm this approach, the meridional Ekman transport $V_{E}$ in the frontal area was calculated (Fig. 5). Directly north of the front, the transport points mainly towards the south with a mean transport of $-0.03 \pm 0.29 \mathrm{~m}^{2} \cdot \mathrm{s}^{-1}$. Contrary to that, directly south of the front a northward pointing Ekman transport $\left(0.05 \pm 0.26 \mathrm{~m}^{2} \cdot \mathrm{s}^{-1}\right)$ is calculated. At the front, the transport is variable with a small northward tendency $\left(0.01 \pm 0.28 \mathrm{~m}^{2} \cdot \mathrm{s}^{-1}\right)$. The meridional Ekman transports north and south of the front form a convergence area within which the AF is located. The north- and southward moving of the front is partially caused by the variability of these transports. Changes in the mean direction of the Ekman transports from south- to northward (e.g. 19911993, 1998-1999, Fig. 5a) north of the AF lead to pronounced positive anomalies of the position of the front (cf. Fig. 4, black line), while the zero crossings of the transport south of the front (1977 and 1996, Fig. 5c) lead to negative anomalies. From 2003 onwards, the meridional transport north of the AF vanishes causing the northward persistent moving of the front leading to the northernmost position in 2005 (Fig. 2a). In the same time period (from 2003 to 2007), the correlation between the NAO and the associated wind direction with the propagation of the AF seems to change, because the leading effect of the NAO with a one year time lag is terminated (Fig. 2 and Fig. 4). To secure this trend with a statistically significant result, further studies with longer time periods, spanning the dominant period of the NAO (approx. 11 years) in minimum, are required.

These results of the influence of the NAO, the associated winds, and Ekman transports in the frontal region on the propagation of the $A F$, represent just some of the possible driving mechanisms. Among this wind driven forcing of the front's propagation, the impact on the AC of the Mediterranean Outflow was shown, by postulating that the $A C$ is possibly conceptually generated by $\beta$-plumes [33-36]. Ref. [36] confirms with observational evidence that both 

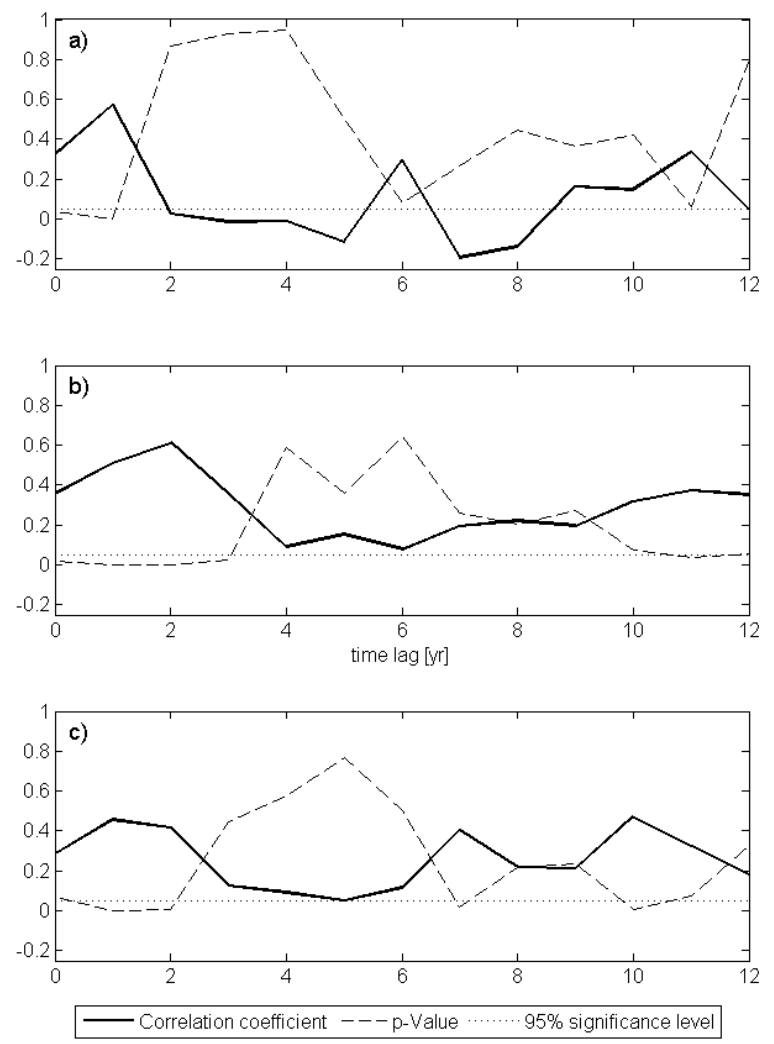

Figure 3. Lagged correlation coefficients between a) winter NAO and the annual mean position of the Azores Front, b) winter NAO and annual mean of GSNW, c) annual mean position of the Azores Front and annual mean of GSNW the first parameter is leading respectively (solid lines). Pvalues (dashed lines) greater than 0.05 (i.e. $95 \%$ significance level, dotted lines) indicate the level for no correlation and independent samples.

mechanisms are coupled, leading to the assumption that variability of the Mediterranean Outflow would influence propagation of the AF as well. However, this issue is subject to further investigations. The focus here lies on the atmospheric forcing because the variability of the atmospheric conditions mainly influences the uppermost water column where the biological production occurs. Changes in the amount of the production are then mirrored in the deep ocean particle flux [16]. In this context of dominant climatic features over the North Atlantic, among the NAO the Atlantic Multidecadal Oscillation (AMO) has to be regarded. In the observed period from 1966 to 2007, the AMO-index shifted from negative to positive in 1997. Nevertheless, a statistically significant influence of this shift from a colder to warmer period in 1997 of the position of the AF cannot be seen, as the dominant period of the AMO of 60 to 80 years [37] is nearly twice as long as
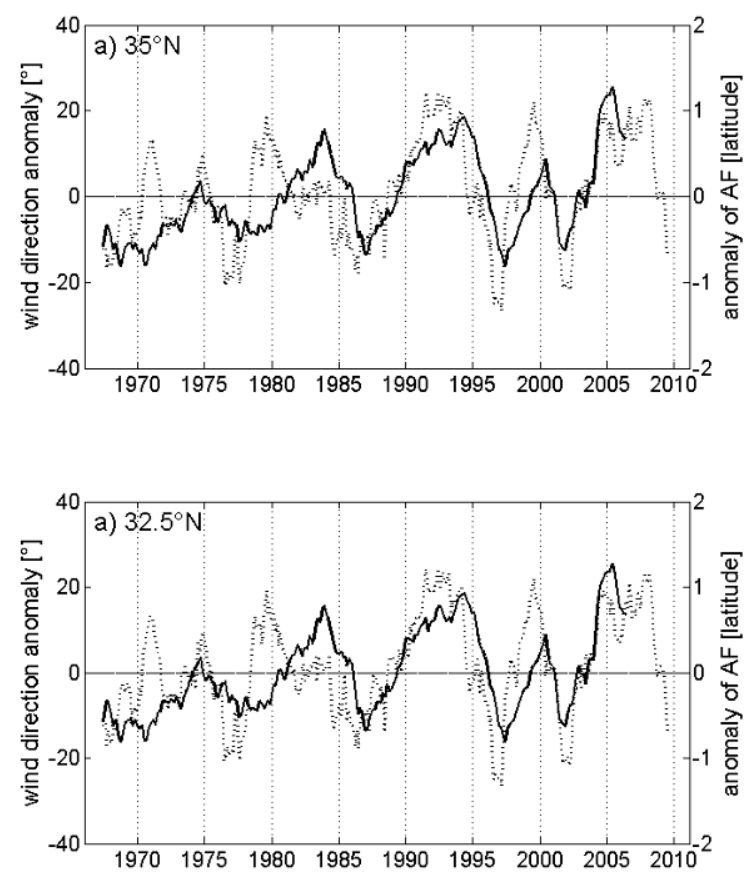

Figure 4. Anomaly of the 36 month running mean of the wind direction (dotted lines) at $22^{\circ} \mathrm{W}$ and running mean over 36 months of the anomaly of the position of the Azores Front (solid lines) at a) $35.0^{\circ} \mathrm{N}$ and b) $32.5^{\circ} \mathrm{N}$. At both latitudes the mean wind direction is southward, so that a positive anomaly indicates a westward and a negative anomaly an eastward deviation.

the time series in which the position of the AF is observed.

\subsection{The Front's Impact on the Gulf Stream}

Among the atmospheric forcing by the NAO on the AF, the coherence of the meridional propagation of the Gulf Stream, with the NAO on one side and with the AF on the other side, is considered by using the GSNW index, which is derived from the position of the Northern Wall of the Gulf Stream.

The meandering of the Gulf Stream is characterized by a high month to month variability which can be removed by calculating a running mean over 36 months (Fig. 2b). The shifting of the northern wall of the Gulf Stream as the northwestern boundary of the North Atlantic Subtropical Gyre shows a similar pattern as the position of the AF with alternating north- and southward movements. A response to the NAO was also seen in the GSNW position in previous studies (e.g. ref. [8, 9]), caused by changes in the wind driven currents. Ref. [9] found that drift of the Gulf Stream was correlated with the NAO with a 2-year lag, whilst ref. [10] found highest correlations with zero or 

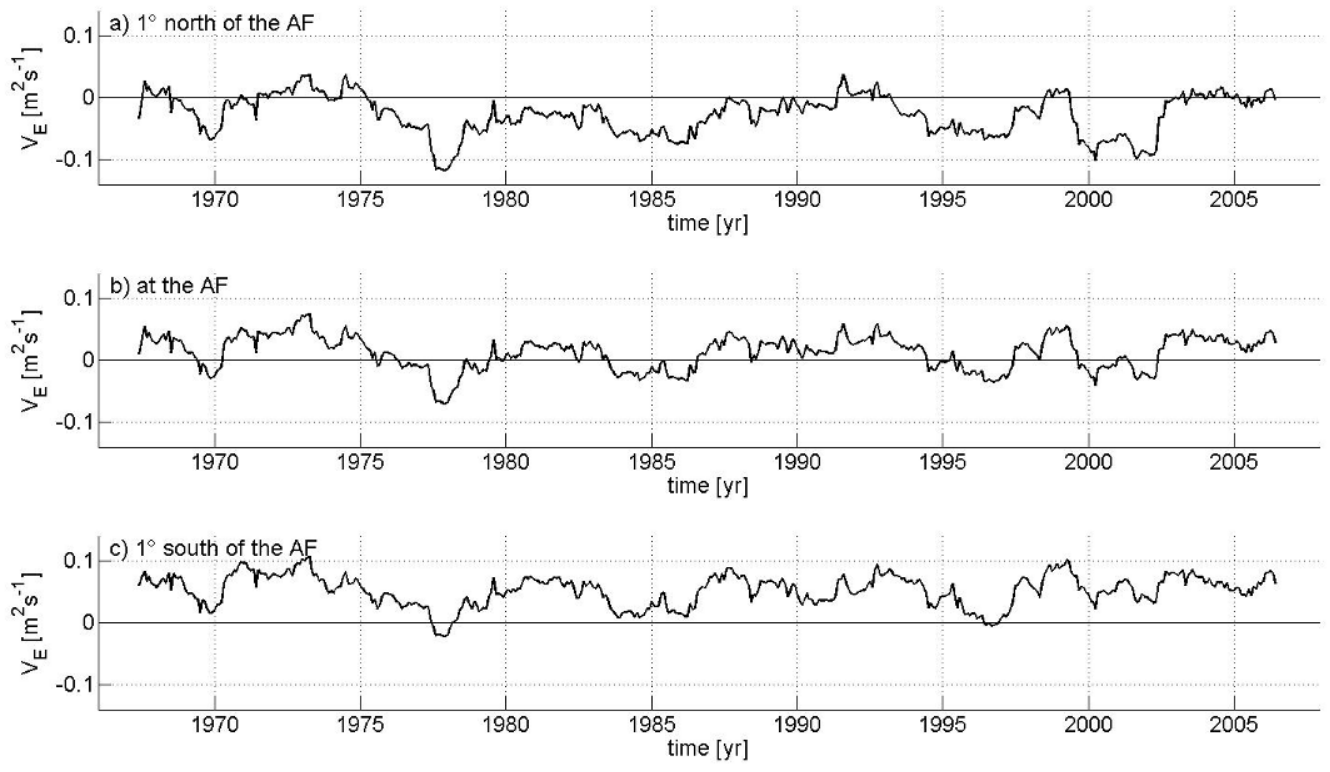

Figure 5. 36 month running mean of the meridional component of the Ekman transport $V_{E}$ at $22^{\circ} \mathrm{W}$ a) $1^{\circ}$ north of the $\left.\mathrm{AF}, \mathrm{b}\right)$ at the $\mathrm{AF}$, and $\left.\mathrm{c}\right) 1^{\circ}$ south of the AF.

one year lag. In this study, correlations show significant coefficients with lags of zero to three years and of eleven years $(\rho=0.37)$, with the highest coefficient $(\rho=0.61)$ at a two years lag (Fig. 3, Table 3). The adjustment of the Gulf Stream position to the changes in forcing is determined by westward propagation of baroclinic Rossby waves which may take several years to cross the North Atlantic [11]. Comparing the correlations between NAO and the position of the AF on one side and the NAO and the GSNW on the other side, the GSNW seems to respond later to the NAO than the AF (Fig. 3, Table 3).

Correlation coefficients between the position of the $A F$ and the GSNW were calculated for both the monthly and annually averaged time series (Table 3). First, considering the correlation where the shift of the AF is a response to changes of the GSNW, only low correlations ( $\rho \leq 0.15$, Table 3) at different lags were found in monthly resolution, whereas in annual resolution no significant correlations were determined at all. Compared to the atmospheric forcing of the propagation of the AF by the NAO, motions of the Gulf Stream seem to affect the AF less.

Considering the results of the correlation between the NAO and both the GSNW and the position of the AF, correlation coefficients for the GSNW lagging the AF were calculated (Table 3). In monthly resolution, significant correlations were found when the GSNW is responding to the shifting of the AF, at a lag of 14 months with the highest coefficient of $\rho=0.23$, and at a lag of 26 months
( $\rho=0.14)$, then with a lag of 87 months $(\rho=0.19)$, and at last where the GSNW lags the position of the AF by 117 months $(\rho=0.23)$. In contrast to the correlations where the AF responds to the GSNW, here a response of the GSNW to the AF is also reflected in the annual calculations (Fig. 3): significant correlations were calculated at lags of one $(\rho=0.45)$, two $(\rho=0.41)$, seven $(\rho=0.4)$ and ten years $(\rho=0.47)$. These results indicate that the NAO first affects the AF with a lag of one year, when the ocean has adjusted to the associated modification of the wind system. The changes of the position of the AF then influence the drift of the North Wall of the Gulf Stream most rapidly with a lag of one year. This implies that the correlation between the GSNW and the NAO can be explained by a direct response of the GSNW to the position of the AF whereby the influence of the NAO on the GSNW is most likely caused by an indirect signal transfer via the Azores Front.

The NAO has a high impact on the SST pattern of the North Atlantic with a largest correlation at a zero lag [38]. Considering the position of the $A F$ at $22^{\circ} \mathrm{W}$, ref. [39] shows (in their Figure 18) that a positive NAO-index leads to a positive temperature anomaly and vice versa. This temperature anomaly pattern is transferred across the Atlantic as Rossby Waves. Ref. [40] have shown that the AC can amplify the westward propagating Rossby Waves and has a similar waveguide effect as observed in the Antarctic Circumpolar Current [41]. 
The correlation coefficients of the annual means have shown four different time lags in the range of one to ten years between the latitude of the AF and the GSNWindex. This slow signal transfer across the North Atlantic is in the same order as the magnitude of Rossby Wave propagation. With a typical wave speed of $10-15 \mathrm{~cm} \cdot \mathrm{s}^{-1}$ [42] the NAO induced SST pattern in the region of the AF needs one to two years to reach the west coast of the Atlantic where the drift of the Gulf Stream is observed. Much lower wave speeds have been quantified by ref. [40], with $0.9 \mathrm{~cm} \cdot \mathrm{s}^{-1}$ and $1.9 \mathrm{~cm} \cdot \mathrm{s}^{-1}$. These speeds indicate that the signals are able to cross the Atlantic in seven and ten years; time lags for which high correlations between the $\mathrm{AF}$ and the GSNW were found (Fig. 3).

\subsection{Impact on Deep Ocean Particle Flux}

The deep ocean particle flux from 1994 to 2008 is shown in Fig. 6. A detailed description of the particle fluxes from 1994 to 2002 is given in ref. [16]; the period from February 2002 to March 2005 was analyzed by ref. [43] and ref. [26]. The particle flux time series show a high seasonal and interannual variability mirroring the variability in primary production [16]. The annual maximum of particle flux varies in time from February to May. The highest values are found in 2004 with more than $250 \mathrm{mg} \cdot \mathrm{m}^{-2} \cdot \mathrm{day}^{-1}$ and in 2005 with $350 \mathrm{mg} \cdot \mathrm{m}^{-2} \cdot \mathrm{day}^{-1}$. The seasonal variability follows directly the phytoplankton development and decay within the euphotic zone [16]. The annual maximum is initiated by the decay of the bloom with a delay of approximately one month resulting from a mean sinking velocity of $100 \mathrm{~m} \cdot \mathrm{day}^{-1}$ [29]. Comparison of independently predicted primary production with the particle flux in $2000 \mathrm{~m}$ depth shows a direct correlation between these two variables, but any influence of the variability in the catchment areas of the sediment trap was overlaid by the stronger signal of the seasonal cycle [16]. Ref. [16] suggests that the interannual variability is caused whether the winter mixed layer reaches the nitracline or not. The coupling of the seasonality of the winter mixed layer depth and the seasonality of phytoplankton biomass was postulated by ref. [24] for the ESTOC station near the Canary Islands. In the region of the Madeira Basin, where the mooring station KIEL276 is located, the deepening of the winter mixed layer reaches its maximum in winter to early spring (Fig. 6). The maximum varies from nearly $80 \mathrm{~m}$ north of the AF in 1995 to $190 \mathrm{~m}$ in 2005 south of the AF caused by a lifting of the isotherms by the front in the north (Fig. 7). Ref. [15] found values of $150-170 \mathrm{~m}$ in the region of the AF in the winter 1980/81 derived from the deep stability maximum, a MLD depth range that is in good agreement with the magnitude of the mixed layer depth derived from assimilated modeled temperature fields. In spring and summer the seasonal stratification begins and the mixed layer shallows to its minimum in autumn. If the mixed layer is deeper than the nutricline, new nutrients are supplied to the upper water column followed by phytoplankton growth. A comparison of the timing of the deepest mixed layer, which corresponds with the maximum of phytoplankton abundance in the euphotic zone, and the maximum in particle flux shows a delay of about 30 days due to the sinking velocity. Due to the coarse monthly resolution of the MLD in addition to the sampling intervals of the particle flux of two weeks to two months, ref. [26] estimated slightly longer time lags ranging from 30 to 60 days (Fig. 6).

To investigate the influence of the $\mathrm{AF}$ on the interannual variability of the particle flux, the different biological environments north and south of the AF are considered. Using remotely measured chlorophyll $a$ values in this region allows only to account for particular issues, e.g. beginning of the spring bloom, but not for the existence of the deep chlorophyll maximum (DCM) in 50 - $120 \mathrm{~m}$ [7] which is not detectable by satellite measurements. Ref. [15] found higher integrated chlorophyll $a$ values, as well as a higher maximum chlorophyll $a$ concentration in the DCM in the Eastern North Atlantic Water (ENAW) that is colder and generally lies north to the $A F$, in comparison to the warmer Western North Atlantic Water (WNAW) south to the AF. Also, the zooplankton biomass was significantly higher in ENAW than in WNAW. Due to the lower integrated chlorophyll $a$ values, the euphotic zone (1\% light level) in the WNAW was $14 \mathrm{~m}$ deeper, causing a $20 \mathrm{~m}$ deeper DCM [15]. In contrast ref. [7] analyzed 13 cruises from 1992 to 2001 in the AF region and found no significant latitudinal trend in depth-integrated chlorophyll $a$. The integrated primary production showed high values both north and south of the AF, as well as in the frontal boundary. In agreement with ref. [15], a $20 \mathrm{~m}$ shallower DCM north of the AF was seen by ref. [7], but they attributed the upward trend of the DCM towards northern latitudes to cooler surface waters and shallower mixed layers. It should be noted that the sampling resolution cannot resolve the mesoscale activity [7] which can induce high primary production (cf. [15]) caused by eddies affecting up- or downwelling relative to their direction of rotation [44]. It is one of the most important requirements for the phytoplankton bloom that the MLD in winter reaches the nutricline depth to supply new nutrients by mixing. The depth of the nutricline is highly correlated with the depth of the DCM [7], so that a mean difference of the nutricline depth of $20 \mathrm{~m}$ is expected between positions north of the AF (shallower) and south of the AF (deeper).

Assuming the same winter mixed layer depth north and 


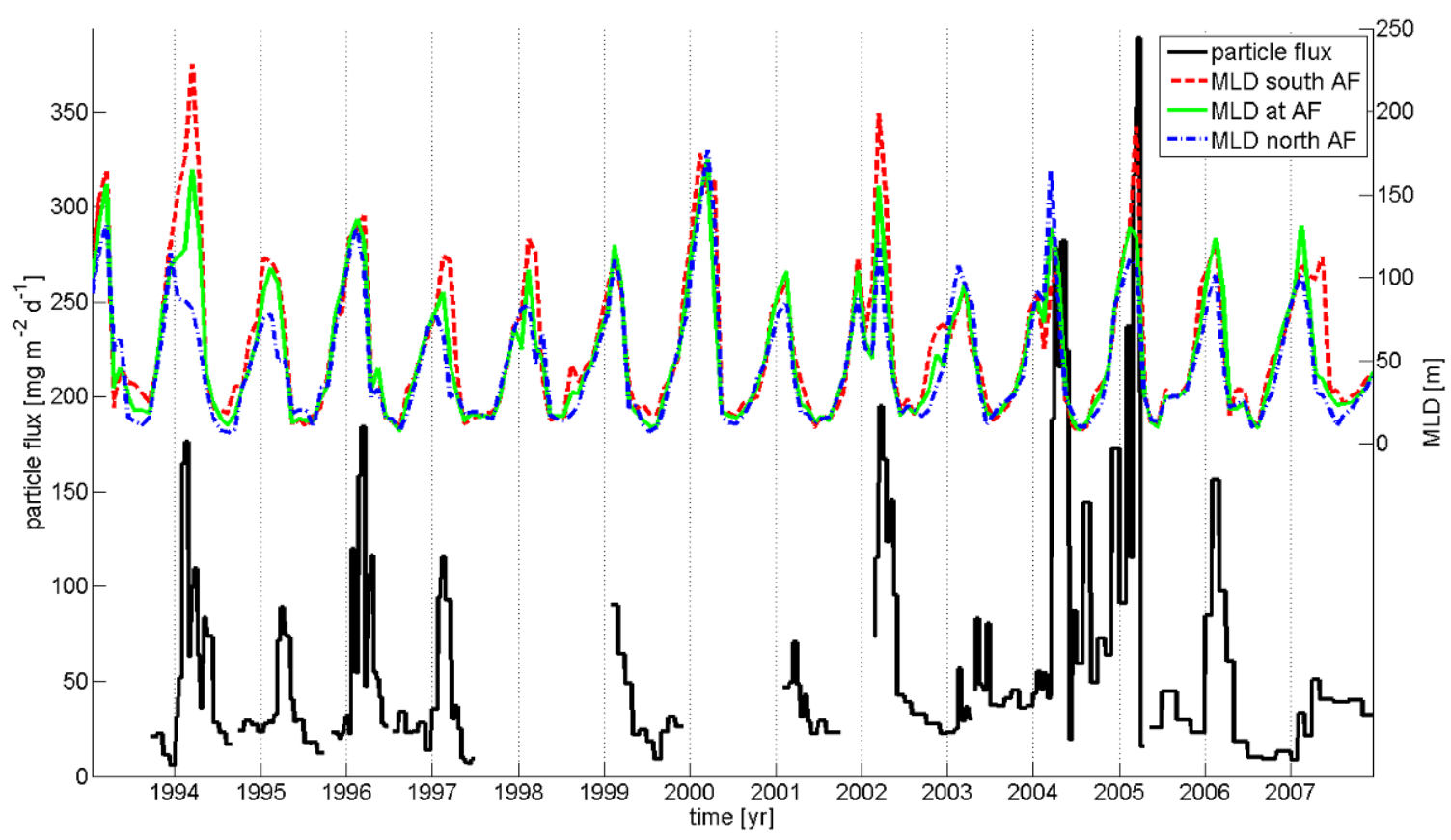

Figure 6. Particle flux at $2000 \mathrm{~m}$ depth at KIEL276 (black line) and mixed layer depths at the position of the AF (green line), $1^{\circ}$ latitude north of the front (dot-dashed blue line) and $1^{\circ}$ latitude south of the front (dashed red line). The gaps in particle flux between June 1997 and February 1999 and between April 2000 and 2001 are caused by mooring failure.

south of the front, more nutrients would be supplied in the north due to mixing because the water column generally contains higher nutrient concentrations than south of the $\mathrm{AF}$, where the nutrients are depleted to a greater depth. In addition to the northward trend of the MLD shallowing within the frontal region because of lower surface temperatures, the AF lifts the mixed layer by rising of the isotherms (Fig. 7). Generally, a deeper mixed layer can be seen south of the AF (Fig. 6 and Fig. 7). Further north, in the North Atlantic Drift Province north of the frontal region, the winter mixed layer starts to deepen to reach $350 \mathrm{~m}$ in March [45]. From 1966 to 2007 a mean difference in the MLD of $10 \mathrm{~m}$ was calculated with $50 \pm 40 \mathrm{~m}$ north of the AF and $60 \pm 50 \mathrm{~m}$ south of the AF. The high standard deviation is caused by the high seasonal variability with a shallow mixed layer of approximate $10 \mathrm{~m}$ in summer. Just considering the annual maximum MLD in winter, a difference of about $40 \mathrm{~m}$ between south $(150 \pm 40 \mathrm{~m})$ and north $(113 \pm 25 \mathrm{~m})$ of the AF was determined. The lifting of the lower isotherms in the water column by the front is superimposed by mesoscale eddy activity acting on the MLD, so that a high interannual variability both in the depth of the mixed layer and the difference relative to the front is seen (Fig. 6). Assuming that there are no, or only small, differences between the MLD north and south of the AF (e.g. 1996), a higher primary production north of the AF is expected due to a shallower nitracline (Fig. 7) providing more nutrients. In contrast, in March 1994 the MLD north and south of the AF shows a difference of nearly $150 \mathrm{~m}$ which provides more nutrients to the south and may lead to an enhanced primary production at the southern frontal boundary (Fig. 7). In-situ nitrate measurements north and south of the AF from April 2007 are used to estimate the amount of dissolved nitrate supplied to the euphotic zone - through deepening of the mixed layer in winter - by integrating the nitrate content over the MLD. Assuming the different mean maximum MLDs with their standard deviations derived from SODA POP, in this case twice as much nitrate $\left(69_{-36}^{+123} \mathrm{mmol} \cdot \mathrm{m}^{-2}\right)$ is delivered south of the front compared to north of the frontal system $\left(33_{-18}^{+32} \mathrm{mmol} \cdot \mathrm{m}^{-2}\right)$.

The mooring station KIEL276 located on $33^{\circ} \mathrm{N}$ is frequently passed by the AF so that catchment areas of the sediment trap of up to a few hundred kilometers [16] have to be considered for relating the MLD, depending on the $A F$, with the particle flux. Even if the time series station is located south of the AF, a catchment area of a few hundred kilometers can deliver particles originating north of the AF and vice versa. Induced by the high eddy activity 


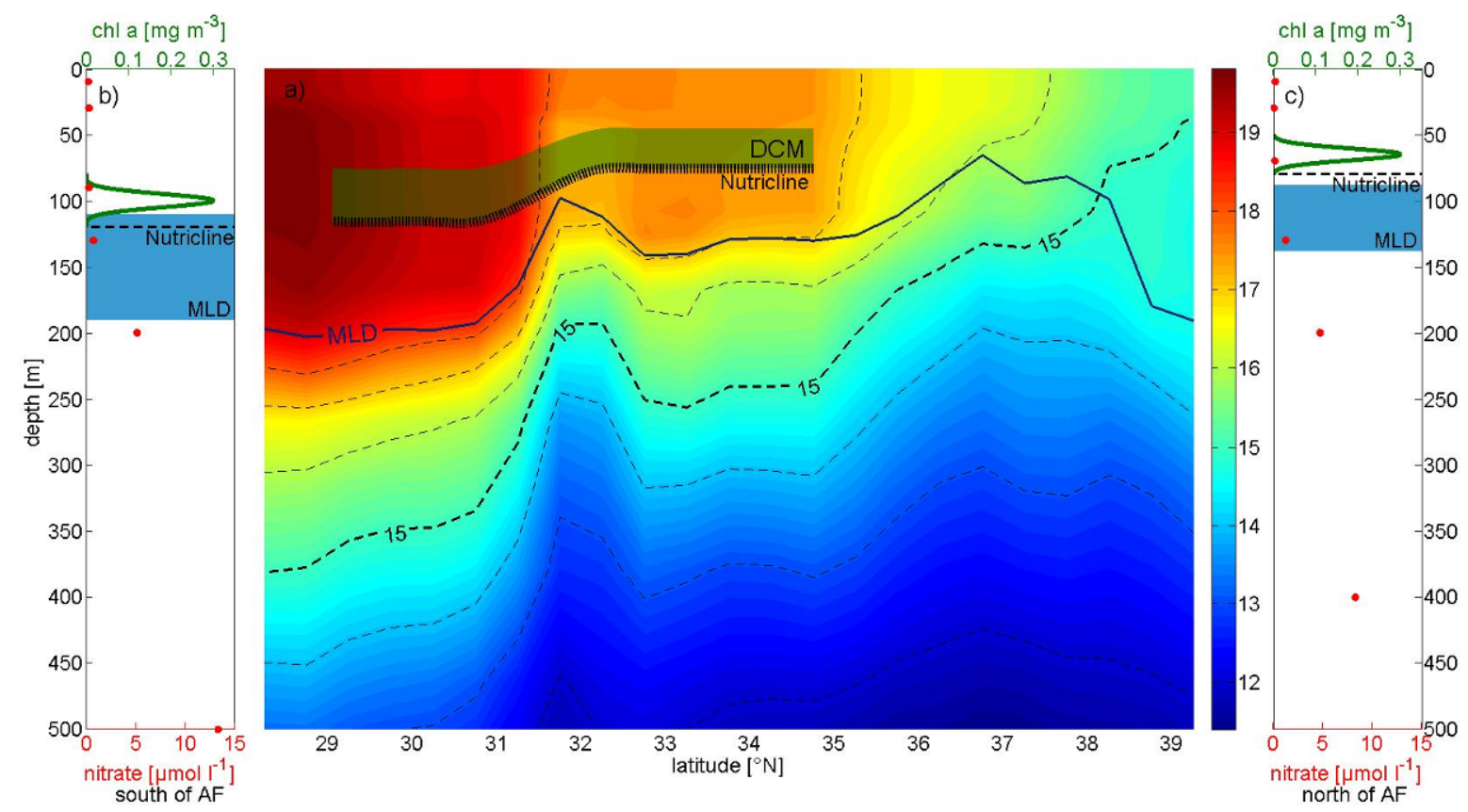

Figure 7. a) Temperature distribution from March 2002 derived from SODA POP and the mixed layer depth (MLD) is shown. In the region directly located at the $\operatorname{AF}\left(31.5^{\circ} \mathrm{N}\right)$ the deep chlorophyll maximum (DCM) and the nutricline is schematically assigned. b) and c) Schema of the DCM in $80-120 \mathrm{~m}$ south to the AF and in $50-80 \mathrm{~m}$ north to the front as well as the nitracline. Also displayed are the depth range of the winter MLD derived from SODA POP, and in-situ nitrate measurements of the cruise P349 (red circles) in April 2007.

at the frontal boundary, the currents in the upper water column down to $1000 \mathrm{~m}$ show high variability in velocity and direction values (e.g. [16, 30]), leading to high variations in extent and orientation of the catchment areas of the sediment trap.

The catchment areas as well as the position of the AF at the time when the MLD reaches the maximum in winter were used to determine if the particle flux originated north, south or at the front. These considerations provide information which maximum MLD - the generally deeper in the southern frontal region, or the shallower in the northern part - has existed in the origin area of the annual maximum particle flux. The relationship between this annual maximum MLD in winter and the particle flux is shown in Fig. 8 (black circles).

A regression line of

Particle flux $\left[\frac{m g}{m^{2} \text { day }}\right]=2.25\left[\frac{m g}{m \text { day }}\right] \times \operatorname{MLD}[m]-130\left[\frac{m g}{m^{2} \text { day }}\right]$

was calculated. With one exception, all values are within the $95 \%$ significance level. The correlation coefficient of 0.84 (99\% significance level) between the particle flux and its corresponding MLD, justifies the linear regression in this frontal region.
If the catchment areas as well as the position of the front are not taken into account, no relationship between the winter MLD (north, south or at the front) and the particle flux exists which is evident from the wide scattering (Fig. 8). Applying the regression line (1) (Fig. 8) the particle flux would be depleted when the MLD is shallower than $58 \mathrm{~m}$. This result agrees well with the measured depths of the deep chlorophyll $a$ maximum between 50 and $80 \mathrm{~m}$ in the northern frontal region [7], because a MLD of $58 \mathrm{~m}$ would not reach the nutricline located below the DCM and no nutrients would be delivered to the euphotic zone, causing termination of the primary production and eventually of particle flux. Thus the winter MLD is the determinant for the interannual variability of the primary production leading to the observed variability in particle flux.

\section{Conclusions}

The analyses of the position of the AF derived from assimilated modeled temperature fields between 1966 and 2007 show that this front is a highly dynamic system with a great variability of north- and southward propagation 


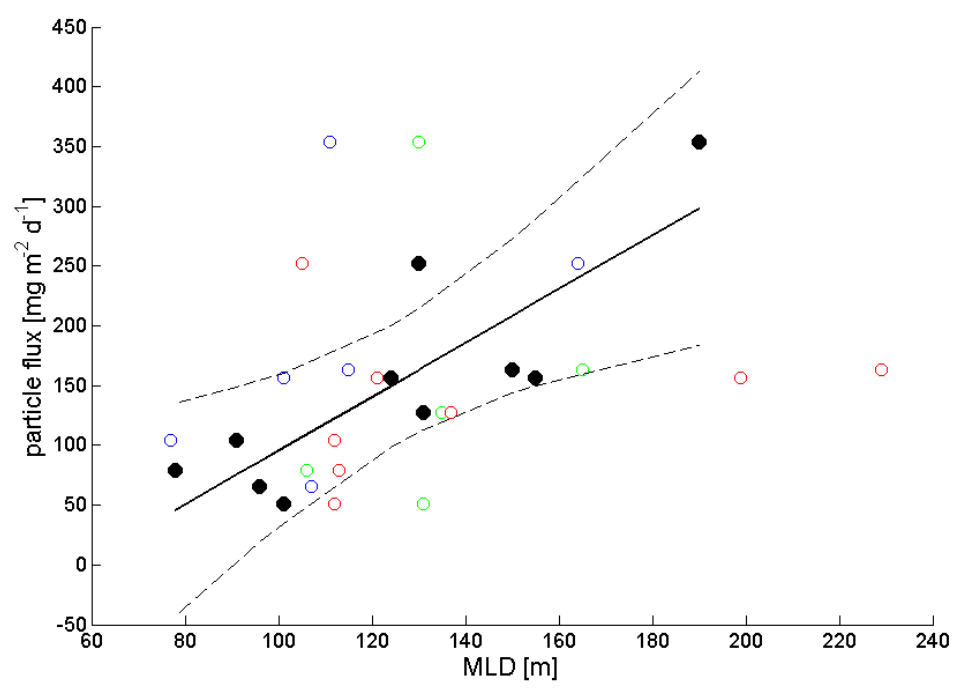

Figure 8. Annual maxima of the particle flux in $2000 \mathrm{~m}$ depth (1994 - 1997, 2002 - 2007) are assigned to the annual maxima of the MLD (black circles). The location of the catchment areas according to the position of the AF either north, south or at the front was taken into account. A linear regression (solid line) with the $95 \%$ significance levels (dashed lines) was calculated. Additionally, the annual maxima of the particle flux north (blue circles) and south (red circles) of the AF as well as at the front (green circles) in relation to the annual maxima of the MLD are shown.

on monthly to decadal time scales. The southernmost position was found at $30^{\circ} \mathrm{N}(2004)$ and the northernmost at $37.5^{\circ} \mathrm{N}$ (1975 and 2004) with an overlying northward shifting trend of $6 \mathrm{~m} \cdot \mathrm{day}^{-1}$.

The propagation of the front is mainly forced by atmospheric conditions determined by the North Atlantic Oscillation. Wind direction changes over the North Atlantic, correlated with the NAO, cause advection and convergence/divergence which induces periodical movement of the front. The Ekman transports, due to the wind field in the frontal region, lead to a convergence zone with northward transport south to the front and southward transport north to the front. Variability of these transports causes additional meridional shifting of the front. It is possible that a change in trend of the correlation between the NAO and the propagation of the AF occurred in 2003, but further investigations are needed for a statistically significant result.

Due to the front's location further to the east in the North Atlantic than the Gulf Stream, fluctuations of the atmospheric patterns centered in the western North Atlantic impact the AF and its associated currents faster than the western boundary currents. Rossby waves, modified by movement of the $A F$, then transport the atmospherically initiated signals over the North Atlantic so that the front's shift is mirrored in the variance of the position of the Northern Wall of the Gulf Stream.

The deep ocean particle flux and the concurrent biological production in the upper water column are closely related to the migration of the AF. Correlated variability in the winter mixed layer depth influences the amount of nutrient supply and leads to a high variability in primary production and consequently in particle flux. The front forms a transition zone with particular growth conditions between the cooler and generally more productive water to the north and the warmer less productive WNAW to the south where the general latitudinal trend of increasing primary production to the north is masked. To understand the interannual variability of the deep ocean particle flux it is important to consider the propagation of the AF as well as the associated mesoscale eddy activity at the frontal boundary, which influences the deepening of the mixed layer and furthermore, the variability of the catchment areas due to changes in the current velocities and directions. The resulting variances of the hydrographic conditions in the frontal area are directly mirrored in the strength of primary production in the upper water column and the associated particle flux.

\section{Acknowledgements}

The authors thank all colleagues involved in obtaining the time series data since 1980, the crew and masters of the RV Poseidon and RV Meteor, and two anonymous referees for their comments on earlier versions of the manuscript. 
This work is financially supported by DFG (Contract numbers WA2157/3-1 and WA2157/5-1).

\section{References}

[1] W. J. Gould, Physical oceanography of the Azores front. Prog. Oceanogr.y, 14, 1985, 167-190

[2] W. Krauß, Nr. 258. Sonderforschungsbereich133. Warmwassersphäre des Atlantiks - Eine Dokumentation, Kiel: Berichte aus dem Institut für Meereskunde, 1994

[3] B. Klein, G. Siedler, On the Origin of the Azores Current. J. Geophys. Res., 94, 1989, 6159-6168

[4] R. Schiebel, J. Waniek, A. Zeltner, M. Alves, Impact of the Azores Front on the distribution of planktic foraminifers, shelled gastropods, and coccolithophorids. Deep Sea Research Part II: Topical Studies in Oceanography, 49, 2002, 4035-4050

[5] F. F. Pérez, M. Gilcoto, A. F. Ríos, Large and mesoscale variability of the water masses and the deep chlorophyll maximum in the Azores Front. J. Geophys. Res., 108, 2003, 3215

[6] R. H. Käse, G. Siedler, Meandering of the subtropical front south-east of the Azores. Nature, 300, 1982, 245-246

[7] E. Teira, B. Mouriño, E. Marañón, V. Pérez, M. J. Pazó, P. Serret, D. de Armas, J. Escánez, E. M. S. Woodward and E. Fernández, Variability of chlorophyll and primary production in the Eastern North Atlantic Subtropical Gyre: potential factors affecting phytoplankton activity. Deep Sea Research Part I: Oceanographic Research Papers, 52, 2005, 569-588

[8] A. H. Taylor, M. B. Jordan, J. A. Stephens, Gulf Stream shifts following ENSO events. Nature, 393, 1998, 638

[9] A. H. Taylor, J. A. Stephens, The North Atlantic Oscillation and the latitude of the Gulf Stream. Tellus, 50A, 1998, 134-142

[10] T. M. Joyce, C. Deser, M. A. Spall, The Relation between Decadal Variability of Subtropical Mode Water and the North Atlantic Oscillation, J. Climate, 13, 2000, 2550-2569

[11] C. Frankignoul, G. de Coëtlogon, T. M. Joyce, S. Dong, Gulf Stream Variability and OceanAtmosphere Interactions, J. Phys. Oceanogr., 31, 2001, 3516-3529

[12] C. Eden, T. Jung, North Atlantic Interdecadal Variability: Oceanic Response to the North Atlantic Oscillation (1865-1997). J. Climate, 14, 2001, 676-691

[13] J. Marshall, Y. Kushnir, D. Battisti, P. Chang, A. Czaja, R. R. Dickson, J. W. Hurrell, M. S. McCartney, R. Saravanan, M. Visbeck, North Atlantic Climate Vari- ability: Phenomena, Impacts and Mechanisms. Int. J. Climatol., 21, 2001, 863-1898

[14] E. Fernández, R. D. Pingree, Coupling between physical and biological fields in the North Atlantic subtropical front southeast of the Azores. Deep Sea Research Part I: Oceanographic Research Papers, 43, 1996, 1369-1393

[15] M. J. R. Fasham, T. Platt, B. Irwin, K. Jones, Factors affecting the spatial pattern of the deep chlorophyll maximum in the region of the Azores front. Prog. Oceanogr., 14, 1985, 129-165

[16] J. J. Waniek, D. E. Schulz-Bull, T. Blanz, R. D. Prien, A. Oschlies, T. J. Müller, Interannual variability of deep water particle flux in relation to production and lateral sources in the northeast Atlantic. Deep Sea Research Part I: Oceanographic Research Papers, 52, 2005, 33-50

[17] J. A. Carton, B. S. Giese, S. A. Grodsky, Sea level rise and the warming of the oceans in the Simple Data Assimilation (SODA) ocean reanalysis. J. Geophys. Res., 110, 2005, doi:10.1029/2004JC002817

[18] J. A. Carton, B. S. Giese, A Reanalysis of Ocean Climate Using Simple Ocean Data Assimilation (SODA). Mon. Weather Rev., 136, 2008, 2999-3017

[19] J. W. Hurrell, Decadal Trends in the North Atlantic Oscillation: Regional Temperatures and Precipitation. Science, 269, 1995, 676-679

[20] E. Kalnay, The NCEP/NCAR 40-Year Reanalysis Project, B. Am. Meteorol. Soc., 77, 1996, 437-471

[21] A. E. Gill, Atmosphere-Ocean Dynamics, Academic Press, New York, 1985

[22] I. Alvarez, M. Gomez-Gesteira, M. deCastro, E. M. Novoa, Ekman transport along the Galician Coast (NW, Spain) calculated from QuikSCAT winds. J. Marine Syst., 72, 2008, 101-115

[23] B. A. Ward, J. J. Waniek, Phytoplankton growth conditions during autumn and winter in the Irminger Sea, North Atlantic. Marine Ecology - Progress Series, 334, 2007, 47-61

[24] S. Neuer, A. Cianca, P. Helmke, T. Freudenthal, R. Davenport, H. Meggers, M. Knoll, J. M. SantanaCasiano, M. González-Davila, M.-J. Rueda, O. Llinás, Biogeochemistry and hydrography in the eastern subtropical North Atlantic gyre. Results from the European time-series station ESTOC. Prog. Oceanogr., 72, 2007, 1-29

[25] V. Pérez, E. Fernández, E. Marañón, X. A. G. Morán, M. V. Zubkov, Vertical distribution of phytoplankton biomass, production and growth in the Atlantic subtropical gyres. Deep Sea Research Part I: Oceanographic Research Papers, 53, 2006, 1616-1634

[26] J. Brust, D. E. Schulz-Bull, T. Leipe, V. Chavagnac, 
J. J. Waniek, Descending particles: From the Atmosphere to the deep ocean - A time series study in the subtropical NE Atlantic. Geophys. Res. Lett., 38, 2011, 1-5

[27] K. Kremling, U. Lentz, B. Zeitschel, D. E. SchulzBull, J. Duinker, New type of time-series sediment trap for the reliable collection of inorganic and organic trace chemical substances. Rev. Sci. Instrum., 67, 1996, 4360-4363

[28] J. J. Waniek, D. E. Schulz-Bull, J. Kuss, T. Blanz, Long time series of deep water particle flux in three biogeochemical provinces of the northeast Atlantic. J. Marine Sys., 56, 2005, 391-415

[29] J. Waniek, W. Koeve, R. D. Prien, Trajectories of sinking particles and the catchment areas above sediment traps in the northeast Atlantic. J. Marine Res., 58, 2000, 983-1006

[30] G. Siedler, L. Armi, T. J. Müller, Meddies and decadal changes at the Azores Front from 1980 to 2000. Deep Sea Research Part II: Topical Studies in Oceanography, 52, 2005, 583-604

[31] K. Grasshoff, K. Kremling and M. Ehrhardt, Methods of Seawater Analysis, Wiley-VCH, Weinheim, 1999

[32] D. L. Volkov, L. L. Fu, Interannual variability of the Azores Current strength and eddy. J. Geophys. Res., 116, 2011, 12

[33] Y. Jia, Formation of an Azores Current due to Mediterranean Overflow in a Modeling Study of the North Atlantic. J. Phys. Oceanogr., 30, 2000, 2342-2358

[34] T. M. Özgökmen, E. P. Chassignet, C. G. H. Rooth, On the Connection between the Mediterranean Outflow and the Azores Current. J. Phys. Oceanogr., 31, 2001, $461-480$

[35] S. Kida, J. F. Price, J. Yang, The Upper-Oceanic Response to Overflows: A Mechanism for the Azores Current. J. Phys. Oceanogr., 38, 2008, 880-895

[36] L. Lamas, Á. Peliz, I. Ambar, A. Barbosa-Aguiar, N. Maximenko, A. Teles-Machado, Evidence of timemean cyclonic cell southwest of Iberian Peninsula: The Mediterranean Outflow-driven $\beta$-plume? Geophys. Res. Lett., 37, 2010, 5

[37] R. A. Kerr, Atlantic climate pacemaker for millennia past, decades hence? Science, 309, 2005, 41-43
[38] M. Visbeck, E. P. Chassignet, R. Curry, T. Delworth, B. Dickson, G. Krahmann, The Ocean's Response to North Atlantic Oscillation Variability. In: J. Hurrell, Y. Kushnir, G. Ottersen, M. Visbeck (Eds.), The North Atlantic Oscillation: Climatic Significance and Environmental Impact. American Geophysical Union, Washington, 2003, 113-146

[39] R. L. Molinari, Information from low-density expendable bathythermograph transects: North Atlantic mean temperature structure and quasi-decadal variability. Prog. Oceanogr., 88, 2011, 131-149

[40] P. Cipollini, D. Cromwell, M. S. Jones, G. D. Quartly, P. G. Challenor, Concurrent altimeter and infrared observations of Rossby wave progatation near $34^{\circ} \mathrm{N}$ in the Northeast Atlantic. Geophys. Res. Lett., 24, 1997, 889-892

[41] C. W. Hughes, The Antarctic Circumpolar Current as a Waveguide for Rossby Waves. J. Phys. Oceanogr., 26, 1996, 1375-1387

[42] P. C. Chu, L. M. Ivanov, O. V. Melnichenko, N. C. Wells, On long baroclinic Rossby waves in the tropical North Atlantic observed from profiling floats. J. Geophys. Res., 112, 2007, doi:10.1029/2006JC003698

[43] J. Brust, J. J. Waniek, Atmospheric dust contribution to deep-sea particle fluxes in the subtropical Northeast Atlantic. Deep Sea Research Part I: Oceanographic Research Papers, 57, 2010, 988-998

[44] R. H. Stewart, Introduction to Physical Oceanography, 2008http://oceanworld.tamu.edu/resources/ocng textbook/PDF" files/book "pdf" files.html

[45] A. Longhurst, Ecological Geography of the Sea, Academic Press, New York, 1998, 166-173

[46] B. Zeitzschel, J. Lenz, H. Thiel, R. Boje, U. Passow, A. Stuhr, Expedition Plankton 89 -Benthos 89, Reise Nr. 10, Insititut für Meereskunde an der Universität Hamburg, Hamburg, 1990

[47] J. Mienert, G. Graf, C. Hemleben, K. Kremling, O. Pfannkuche, D. E. Schulz-Bull, Nordatlantik 1996, Cruise No. 36, 6 June 1996 - 4 November 1996. Insitut für Meereskunde der Universität Hamburg, Hamburg, 1998 